\title{
APPLICATION OF SODIUM ALGINATE CAPSULES AS AN INNOVATIVE METHOD OF ADDING PREPARATIONS
}

\author{
A. P. Minaenko (a)*, Yu. A. Kuchikhin (b), A. N. Zhavnerov (c), V. A. Gribkova (d) \\ *Corresponding author
}

(a) K.G. Razumovsky Moscow State University of Technologies and Management (the First Cossack University), 73, Zemlyanoy Val str., Moscow, Russia, lina111299@mail.ru

(b) K.G. Razumovsky Moscow State University of Technologies and Management (the First Cossack University, 73, Zemlyanoy Val str., Moscow, Russia, kuchikhin@gmail.com

(c) K.G. Razumovsky Moscow State University of Technologies and Management (the First Cossack University) 73, Zemlyanoy Val str., Moscow, Russia, a.zhavnerov@mgutm.ru

(d) K.G. Razumovsky Moscow State University of Technologies and Management (the First Cossack University) 73, Zemlyanoy Val str., Moscow, Russia,vera_gribkova@list.ru

\begin{abstract}
One of the main problems in commercial aquaculture is the difficulty of introducing biologically active components and various preparations into the fish body. To achieve this goal, the development of new methods of application is required. Biocapsules are a new method of introducing dietary supplements. The capsule consists of sodium alginate and is capable of removing various toxicants from the body by diffusion, and is a sorbent. This article describes a study on the use of sodium alginate biocapsules with the introduction of Bacillus subtilis into the body of Cyprinus carpio (Rubrofuscus) (Defined by: LAiman coi identification) to determine the effectiveness of wound healing on the body of fish. As the experiment has shown, the biocapsule is able to better introduce $100 \%$ of the drug into the fish body. At the same time, sodium alginate improves the absorption of the drug. The technology of these capsules makes it possible to introduce various kinds of preparations that were previously impossible for introduction into the body of fish.
\end{abstract}

2672-8575 C 2022 Published by European Publisher.

Keywords: Aquariums, biocapsules, bacillus subtilis, calcium lactate, sodium alginate 


\section{Introduction}

Biologically active additives have a beneficial effect not on an organ or system, but on the entire body. Illiterate use or use of dietary supplements can lead to serious consequences affecting the body of fish. It is necessary to take very seriously the choice of dietary supplements and control their mechanisms of influence on the organism of aquatic organisms. Biocapsules are a new technology for packaging biologically active substances for feeding fish, for changing the $\mathrm{pH}$ of a solution in a recirculation system, etc. Biodegradable capsules, due to the content of sodium alginate in them, have a wide range of pharmacological effects, for example, they can be used as sorbents. The mechanism of action of sorbents is aimed at stimulating the release of endotoxicants from the systemic circulation and internal media into the lumen of the gastrointestinal tract by direct diffusion from the blood and / or, to a greater extent, excretion with digestive juices. A number of mechanisms include the indirect enhancement of the metabolism and excretion of toxins by the detoxification organs, as well as the fixation and transfer of biologically active substances, such as enzymes and bile acids, on the surface of the enterosorbent. All this, in general, ensures the removal of toxic substances from the internal environments, a decrease in the load and an improvement in the functioning of the detoxification organs, which, in general, leads to antitoxic and hepatoprotective effects.

\section{Research Questions}

To achieve the goals of the experiment, the following tasks were set:

1. Create a capsule of sodium alginate, which will be actively consumed by fish.

2. Determine the method of application and the concentration of Bacillus subtilis in the biocapsule.

3. Create an experimental setup.

4. Determine the degree of influence of biocapsules on the efficiency of Bacillus subtilis application.

\section{Purpose of the Study}

The aim of the study is to increase the efficiency of commercial fish farming by introducing biologically active additives into fish diets by using biodegradable capsules.

\section{Research Methods}

The capsule manufacturing technology is quite simple and takes place according to the direct spherification method:

1.Preparation of an alginate solution with water or other liquid with continuous stirring.

2. Dissolving calcium lactate in water with continuous stirring.

3. Cooking the spheres. Fill a spherical spoon of the selected size with the alginate mixture. Next, we bring the spoon to the surface of the calcium solution, lower the flavoring base into the calcium water.

4. Flushing the spheres (Molecular cuisine, 2020) 
To create capsules of the required size and density, the preparation technology has been changed. Three containers were taken for cooking. $100 \mathrm{ml}$ was added to container 1. water and 2 grams of dry sodium alginate and stirred until smooth. $100 \mathrm{ml}$ was added to tank 2. water and 5 grams of dry calcium lactate. In tank 3, the capsules were rinsed in water. Capsules were manufactured in different batches during the experiment.

The capsules were made using a mechanical adjustable pipette. Since the solution and capsules are tasteless, colorless and odorless, they will not be absorbed by fish. To create color and taste, a small amount of dye, alginate mixture from tank 1, Alltech Coppens Pre Grower-18 crushed food and Bacillus subtilis were mixed in the container. The resulting mixture was pumped into a pipette and dropped into a calcium lactate solution. In this case, the capsules in this solution did not sink, and the density and thickness of the shell increased depending on the time in the solution. The total residence time in the lactate solution was 3 minutes. Then, using a mesh, the capsules were transferred into container 3 and washed in water. A magnified view of the capsule is shown in Figure 1.

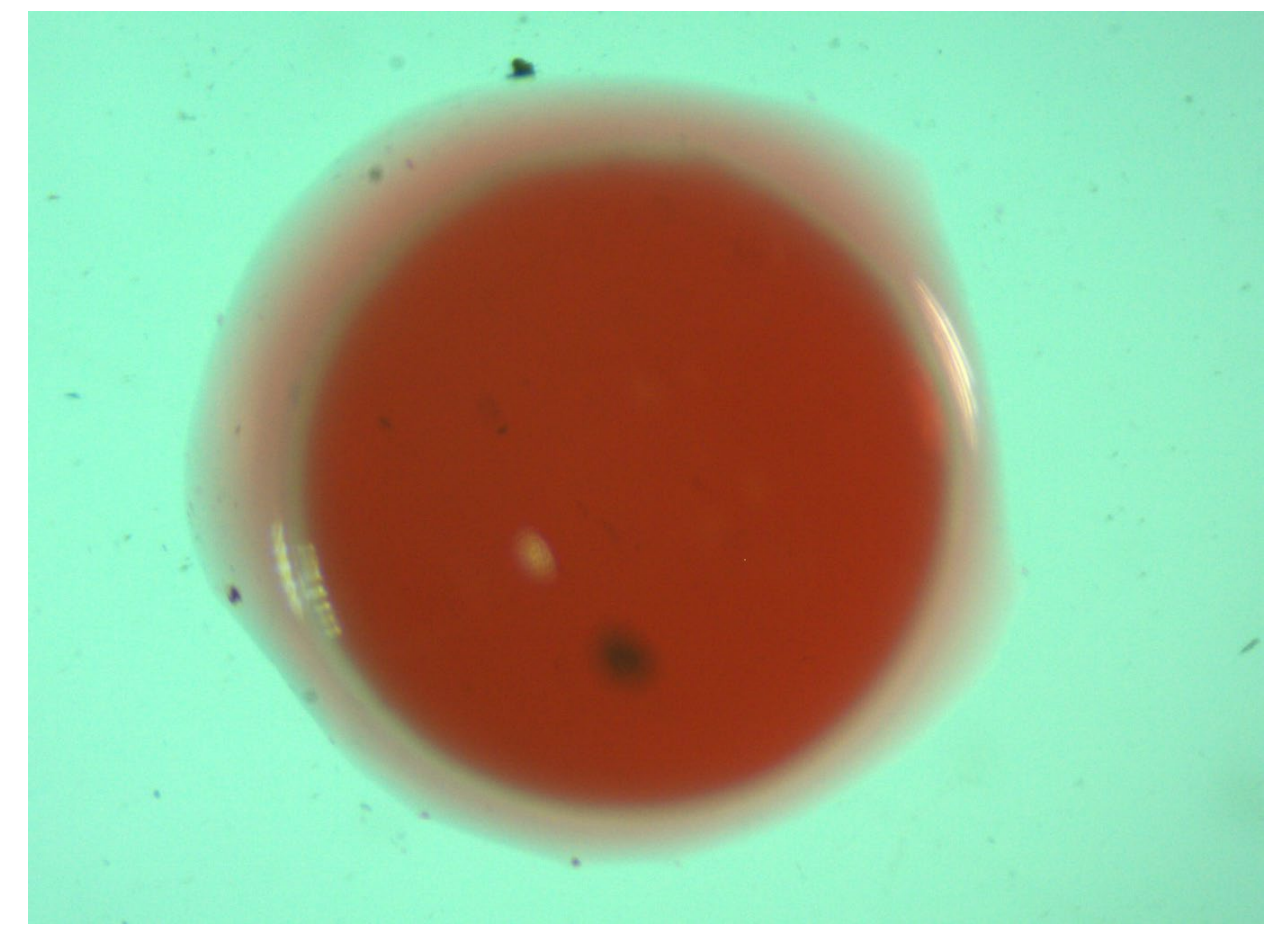

Figure 1. View of the capsule under a magnifying glass after manufacture

During storage of capsules, it was found that the formed membrane is capable of squeezing out structures that do not correspond to it in density. That is, after a certain period of time, all the introduced content was squeezed out into the external environment. Thus, the shelf life of the capsules is the period for removing the introduced contents from it. To determine the shelf life, a batch of capsules with increased dye addition was created and stored under visual observation. After 18 hours, the dye was completely removed from the inner environment of the shell. An additional batch was created with the added probiotic and its release time was the same as that of the dye. The capsule view 18 hours after manufacture is shown in Figure 2. 


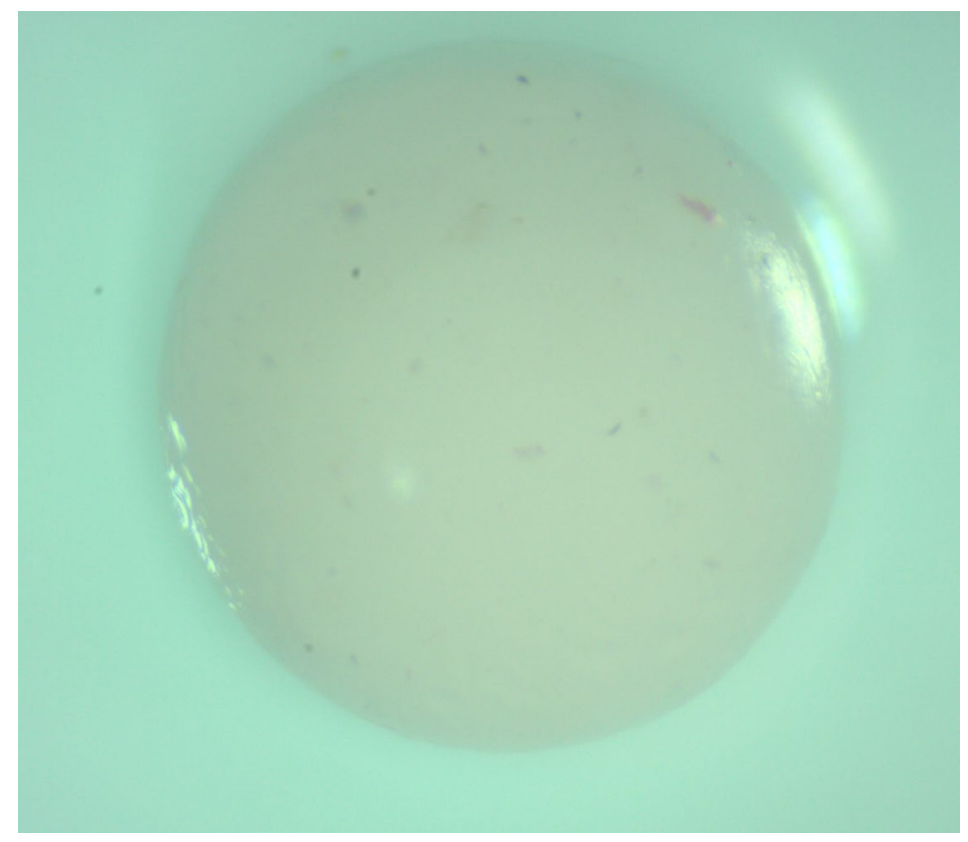

Figure 2. View of the capsule under a magnifying glass after 18 hours

Thus, the storage of capsules takes place in water and is 18 hours.

Bacillus subtilis is applied together with the dye. Subtilis is produced by Research Institute of Probiotics LLC. The amount of subtilis in 1 gram is 5x109 CFU. The capsule weight was 0.02 grams. $5.5 \%$ of the capsule is subtilis. The content of subtilis in 1 capsule is not less than $0.0011 \mathrm{~g}$ and, accordingly, not less than 5500 thousand column-forming units in 1 capsule.

For the experiment, an experimental setup was created, consisting of three aquariums of 200 liters each and a biofilter. The biofilter with a volume of 100 liters consists of: a mechanical coarse filter, a mechanical soft filter, a mesh separator and a sinking bio-load Mbbr K1 kaldnes. The pump pumps water from the biological compartment of the filter and passes it through the UV filter Vitronic 11 W OASE, delivers it to each aquarium through a $20 \mathrm{~mm}$ pipe. The type of biofilter is shown in Figure 3.

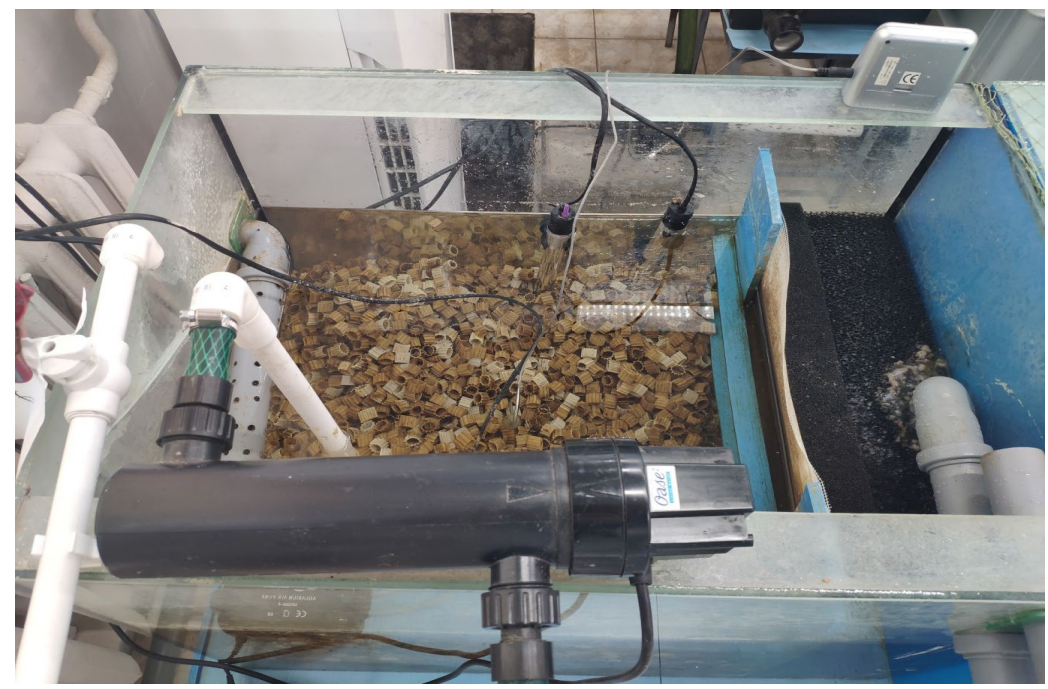

Figure 3. General view of the biofilter 
Water is poured into a biofilter and pumped into the aquariums. After a set of water, it is settled for a day. To maintain the temperature in the installation, 2 Barbus Heater 200w heaters were placed in the biofilter. The temperature throughout the experiment was $24^{\circ} \mathrm{C}$. The water exchange in the installation was 5\% of the total liquid volume per day (Khrustalev et al., 2017; Vlasov, 2012).

For the experiment, we took 9 individuals of Cyprinus carpio (Rubrofuscus), and divided them into 3 control groups (Kovalenko, 2013; Kozlov et al., 2004; Pavlov, 2012):

Group 1: Feeding Alltech Coppens Pre Grower-18 food, in the amount of 1\% of the fish weight per day

Group 2: Feeding Alltech Coppens Pre Grower-18 with Bacillus subtilis impregnation. The volume of feed was $1 \%$ of the weight of the fish, and $0.01 \mathrm{~g}$ of subtilis per day.

Group 3: Feeding with biocapsules with subtilis and Alltech Coppens Pre Grower-18 food. Each fish received 9 capsules per day.

Before starting the experiment, the fish were fed according to the plan.

The essence of the experiment is to determine the effect of sodium alginate biocapsules on the effect of Bacillus subtilis in the rate of regeneration of superficial wounds. For this, a 10x1 mm incision was made on each fish at the base of the dorsal fin on the left side. The fish were weighed before the incision. The fish weighed $92+-7$ grams. After 30 minutes after the incision, the fish were fed and the response to the food was assessed. All groups tolerated the incision well and actively consumed food. The section creation process is shown in Figure 4.

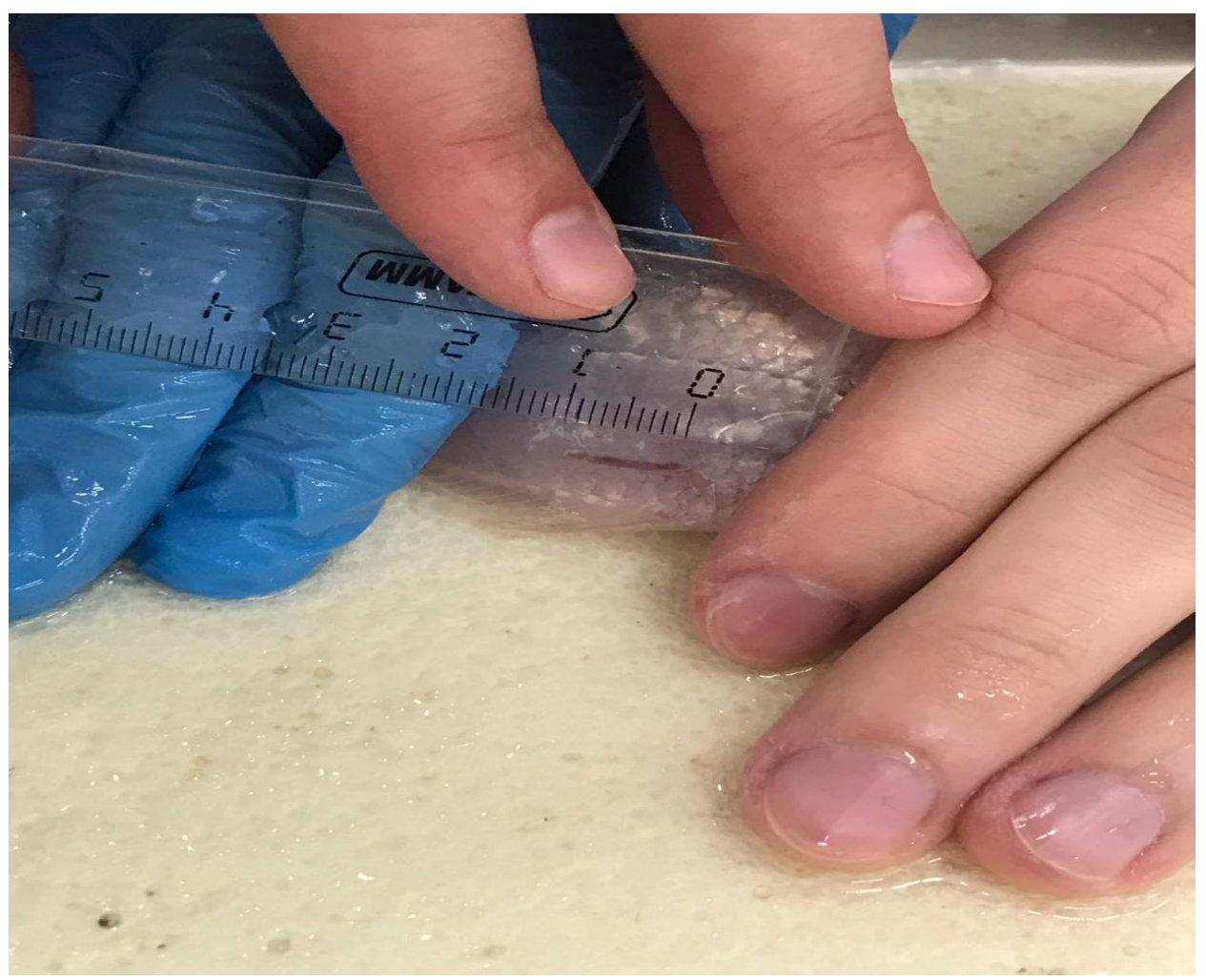

Figure 4. The process of creating a section 
The regeneration of cover structures in juvenile carp weighing 5-10 g at a temperature of $30^{\circ} \mathrm{C}$ occurs within 18 days, at a temperature of $18^{\circ} \mathrm{C}$ it is much slower, and during this time it can only be covered with a film. During the healing process, the epidermis grows on the wound site, some epithelial cells emigrate to the wound area. The wound is healed when the cells of the superficial epidermis tighten its edges, forming a kind of cork, into which cutis grows from all sides. In immature fish, $20 \%$ of the scales are in the stage of regeneration (Amineva \& Yarzhombek, 1984).

\section{Findings}

After the incision, the fish were fed according to the plan for a week and the wounds were measured after 7 days.

In group 1, the wound was not covered with saprolegnia growths, the overgrowth in depth did not exceed $50 \%$. The dynamics of the overgrowth along the length of the wound and the build-up of scales were not observed.

In group 2, overgrowth in depth was $85 \%$. Overgrowth in the length of the wound was observed insignificantly and did not exceed $6 \%$. The initial formation of the scaly cover was not observed.

In group 3, the overgrowth is at least $96 \%$ deep. The overgrowth of the wound in length was at least $27 \%$, in addition, at the site of the incision, the formation of black discs began.

After 14 days from the start of the experiment, the wounds were re-measured.

In group 1, overgrowth in depth was at least $94 \%$. The overgrowth of the wound was at least $7 \%$ in length, and the formation of pigeon discs was not observed.

In group 2, the wound was completely overgrown in depth. The length of the wound was at least $18 \%$. The formation of fluffy discs began.

In group 3, the wound was completely covered with scales.

In group 1, the weakest dynamics of wound growth was observed, however, the fish actively consumed food, and the bleeding stopped on the 3rd day. In groups 2 and 3, the volume of the applied preparation was the same, however, in group 2, the feed was soaked and partially the drug, when it got into the water, came out of the granules, while in group 3 the drug was consumed in full, and sodium alginate improved its absorption.

\section{Conclusion}

To create capsules of sodium alginate suitable for consumption by fish, it is required to reduce the concentration of alginate powder in the solution and add colorants and flavoring premixes to it for detection and consumption by fish. In this case, the density of the capsule shell does not depend on the concentration of sodium alginate, but on the residence time of the capsule in the calcium lactate solution the longer the capsule is in it, the thicker and denser the shell.

The method of processing feed with Bacillus subtilis preparation is imperfect, since the preparation is partially squeezed out of the pellet by water, and also partially remains on the site where the feed and preparation are mixed. 
As the experiment has shown, the biocapsule is able to better introduce $100 \%$ of the drug into the fish body. At the same time, sodium alginate improves the absorption of the drug. The technology of these capsules makes it possible to introduce various kinds of preparations that were previously impossible for introduction into the body of fish. Since capsules have sorbent properties, they are a good option for introducing antibiotics.

\section{References}

Amineva, V. A., \& Yarzhombek, A. A. (1984). Physiology of fish. Light and Food Industry.

Khrustalev, E., Kurapova, T., \& Goncharenko, O. (2017). Feed and feeding in aquaculture. Lan SPB Publishing House.

Kovalenko, M. V. (2013). Feeding koi carp in industrial conditions. In Conditions and ways of development of aquaculture in the light of import substitution (pp 167-172). Amirit.

Kozlov, V. I., Nikiforov-Nikishin, A. L., \& Borodin, A. L. (2004). Aquaculture. Colossus Publishing House.

Molecular cuisine. (2020). All about molecular cuisine, 2020, Retrieved on January 9, 2021, from https://molekula-food.ru/texnika-obratnoj-sferifikacii-process-naoborot

Pavlov, M. V. (2012). Study of the peculiarities of koi carps in aquarium conditions. Collection of scientific papers based on the materials of the XXXV International Scientific and Practical Student Conference, 133-138.

Vlasov, V. A. (2012). Fish farming (2nd Ed.). Lan Publishing House. 